\title{
The study on the innovative teaching method of Internet plus manual training
}

\author{
Liu Qun ${ }^{1, a}$, Cheng Yan², * \\ 1,2 Guangzhou Vocational College of Science and Technology, Guangzhou, 510550, China \\ aemail: 425553879@qq.com, bemail: 305935207@qq.com \\ * the corresponding author
}

Keywords: Internet plus. Manual training. Innovation. Teaching methods.

\begin{abstract}
The present teaching situation of manual training in accounting specialty was described, and the main problems such as single teaching method, inability to meet the different needs of different students at the same time, inability to observe and study repeatedly, and lack of standardization in teaching are pointed out. The innovative teaching method based on internet plus is put forward and its characteristics are summarized. The experiment shows that this innovative teaching method can improve the quality and efficiency of accounting practice teaching, provide reference for the reform of accounting manual practice teaching and curriculum design, and have practical significance for the realization of the goal of accounting personnel training.
\end{abstract}

\section{Introduction}

The integration and development of the Internet and various fields has broad prospects and unlimited potential, and has a strategic and overall impact on China's economic and social development. In 2015, Prime Minister Li Keqiang's government work report put forward the action plan of Internet plus for the first time, and "the Internet plus everything is equal to the future". Accounting manual training teaching has been using the traditional hands-on teaching method for many years. This method that The teachers demonstrate one step and the students follow it is convenient for the students to imitate, but there are also many problems. In view of the problems existing in the teaching of accounting manual training, it is of great significance to carry out innovative research on teaching methods for accelerating the development of Internet plus education and teaching, for cultivating new educational formats and innovative teaching modes, for actively adapting to and leading the new normal development of education, for forming a new kinetic energy of educational development, for achieving higher vocational education quality and efficiency.

\section{The status and problems of accounting manual training}

The existing teaching mode of accounting manual training is mainly based on teacher's lecture, supplemented by student's exercises, decorated with classroom exercises, and individualized guidance should be given according to students'training situation in the process of practice. Therefore, the time allocation in the classroom, the theoretical teaching time is far greater than the training time, and the manual training of hands-on training is contrary to the original intention. At the same time, due to the limited class time, teaching tasks are fixed, most students need to complete training tasks after class, and accounting manual training business is very sequential, a lot of tasks have a sequence, if students encounter problems after class exercises, they will have no way to continue, they can only wait until the next class after the solution to continue to complete. It leads to inefficient training. As time goes by, they can not keep pace with progress and lose interest in study. There are three main problems in this teaching mode as follows.

(1) Teaching method is single.

Most colleges mainly adopt multi-media teaching in accounting manual training. Teachers explain in PPT form. Students fill out vouchers, compile summary forms, register books and 
prepare reports according to the teaching. Because of the limited memory time and brain capacity, many students can only scrap the parts of the lecture. Once there are problems, it is impossible for students to continue training, they can not continue to carry out practical training. Because of the large number of classes, this phenomenon of waiting for teachers to guide is very common, it not only delay time, but also it is easy to make students lose patience and slowly to keep up with the progress, and they will lose interest in training.

(2) It is unable to meet different needs of students at different levels.

Practical courses in most colleges have always been the same as theoretical courses with large classes and only one instructor. Teachers teach according to the teaching progress of the mode of teaching and studying and doing. When they tour to guide individual students'individual problems, they are often too busy to give guidance to each student. If we arrange too much time to solve the problems in the training, it will not only affect the progress of the teaching unit, but also because the given teaching time is shortened, it will result in the lack of comprehensive and in-depth explanation, so that students encounter more problems in the training to result in serious inefficiency in the classroom.

(3) Unable to observe and study repeatedly and lack of standardization in teaching.

Teachers'presentations in class are usually one-off, and students have different levels of learning ability to grasp the speed. Students want to watch more times with no conditions, no video resources can be found. At the same time, different teachers have different lectures, and different classes of the same teacher may produce slightly different lectures due to different teaching time. The same training course can not achieve standardized teaching.

Because of the above problems, manual training courses for many years often can not be completed on time in teaching plan, even if the courses are completed,it is jerry-built to cope with the inspection. The basic accounting skills should have been mastered in the first and second semesters of Basic Accounting Training and Cashier Practice. By the fourth semester of Comprehensive Accounting Training, the teacher was still repeating the main points of the skills, and could not achieve the teaching objectives required by the overall design of each course.

\section{The characteristics of internet plus innovative teaching methods}

In order to solve the shortcomings of the existing teaching mode, combined with the trend of social networking development strategy and the teaching practice experience of accounting manual training teachers, the innovative accounting manual training teaching method of internet plus manual training was present. First of all, the teacher will deliver the teaching task and content to the students in advance on the network platform in the form of documents and videos. Secondly, the teacher will give a brief lecture exercise in class, and the students will ask questions and interact according to the preview and listening situation. Next, the classroom training and teacher on-site guidance will be carried out. The time allocation is roughly 15 minutes of lecture, 5 minutes of questioning and 25 minutes of classroom training. Thirdly, students review after class according to the teaching videos provided by teachers and check the answers in class, and teachers answer the difficult questions online. Finally, the teachers summarize the questions asked by the students after class, and give the answers to the questions.

The improved innovative teaching method has the characteristics as follows.

(1) Combining online and offline, enriching teaching methods and improving students' interest in learning.

The online teaching is carried out in this way. Through the Internet or mobile network platform, the teaching tasks will be transmitted to students before class to preview, send related skills to operate video data for students to watch. After class through the platform uploaded training reference answers for students to check and correct errors, by professional teachers to provide online guidance, timely help students solve questions. This online teaching method can ensure the interaction between teachers and students at any time and anywhere, solve the problems encountered in students' practice in time, and greatly improve the training efficiency.

And offline teaching is carried out in this way. The offline classroom is mainly guided by 
individual tutoring, together with explanations and demonstrations. Briefly explain the relevant theoretical knowledge of practical training, common problems that may be encountered in the process of practical training, and summarize the common problems and difficulties encountered in the process of students' online learning, check the students' completion of practical training, and solve specific problems in the process of practical training. Through theoretical explanation, on-the-spot demonstration, student training, problem review and solution, a virtuous circle is formed. At the same time, online teaching resources are used synchronously in the classroom for most students to learn while doing reference, to ensure that students have reference in every link of learning, improve the efficiency of classroom training.

With the online and offline synchronization and the complement each other, online teaching content is to solve general routine problems, students can learn to grasp through their own view of information, specific problems of individual students will be solved by training teachers in the way of classroom guidance. And the effect of joint guidance and synchronous learning after class can be achieved. With the rapid development of the internet, it is the best choice to combine teaching with internet. Internet plus manual training is not only innovative teaching methods, but also students are more willing to accept. It can greatly enhance students' interest in learning.

(2) Flexible teaching methods to meet the learning needs of students at different levels.

Because of the different understanding and memory of different students, the progress of accounting manual training is quite different. Sometimes it takes students a lot of time to revise and perfect the vouchers because of the irregularities in some places. Online teaching is guided by classroom instruction and online tutoring. Teachers teach difficult knowledge in the limited classroom time, slower understanding of students can use after-class time combined with online tutoring to catch up with progress. Network teaching is not limited by time and space, so students can choose their own learning situation, they have not yet mastered the knowledge to consolidate learning. Teachers can successfully complete the teaching task on the premise of guaranteeing the quality of teaching. Using the method of combining classroom explanation and video recording, students can not only follow the teacher in class, but also can view video learning in places they do not know, it can meet their repetitive learning and the learning needs anytime and anywhere. There is no need to wait for the teacher to solve the problem so as to ensure students' learning needs at different levels, and to improve classroom and curriculum learning efficiency.

(3) Individualization of teaching form.

Whether the computer software or the mobile phone APP network teaching platform, each student registers his own account to log in to study, the system will browse the information, learning process and learning situation to track records, according to different students' learning situation, it will put forward the corresponding personalized learning suggestions, it is conducive to students more effective to grasp relevant knowledge. At the same time, the students' online learning situation is feedback to the teachers, so that the teachers can understand the students' mastery of knowledge and design classroom content for them.

\section{Effect analysis}

Through the teaching comparison of two years in 2015 class accounting major in Guangzhou Vocational College of Science and Technology, it shows that students' training completion rate of each unit is increased by about $20 \%$ because of the Internet plus innovative manual training teaching method, which enhances students' self-confidence in independently completing their learning tasks. Most students learned the accounting manual skills after two years of study. Through the follow-up survey of post practice, the effect of this innovative teaching method is tested again, and the reusability of training resources is enhanced by further optimizing the training teaching resources. On the basis of summing up the successful experience, we can revise the ability target, operation standard requirement and practice time arrangement of manual skill training in accounting professional training plan, and the standardization and systematization of accounting manual skill training will be realized. 


\section{Conclusions}

Through theoretical research and teaching experiments, using the Internet platform such as computers and mobile phones, we can transform the traditional teaching method of teaching and learning and doing into a set of Internet plus manual training innovative teaching methods that are suitable for accounting manual training teaching and focus on cultivating students' autonomous learning habits, so that it can realize the deep integration of Internet and teaching, and improve the teaching effect and quality of accounting manual training course, and give full play to students' subjective initiative so as to change passive acceptance of knowledge to active learning knowledge, and thus the research and practical basis for real classroom reform can be provided.

Of course, the new teaching method requires students to have a strong subjective initiative in learning, students can complete each stage of learning tasks according to the arrangement of teachers, they can take the initiative to think, and their learning attitude is positive and correct. At the same time, the requirements for teachers are also very high, such as reasonable teaching plan, task decomposition ahead of time, ahead of time to complete the relevant video recording, being good at summarizing the problems encountered in the process of students' learning, targeted design of classroom content, and being good at guiding students to complete knowledge teaching according to the new teaching model etc. Only this, the efficiency and effectiveness of teaching can be guaranteed.

\section{References:}

[1] Jiang Xichong. The research on the application of comprehensive practical teaching system of Accounting Specialty in Higher Vocational Colleges[J],Science and Technology Innovation Herald,2014(11).

[2] Luo Chunling. The thinking on the teaching of the course of tax practice under the environment of Finance and information [J], China's management information,2015(22).

[3] Ni Ping.related to construction of practical teaching materials of Higher Vocational Accounting Specialty[J], The new curriculum ,2015(Second).

[4] Chen Xiaoan.Improving practical teaching, improve the professional skills of tax [J],Journal of Inner Mongolia Finance and Economics College,2011(3).

[5] Research Group of finance and taxation. A study on the current situation and problems of the basic theory and skills of the students of finance and taxation specialty and Countermeasures[J],Journal of Inner Mongolia Finance and Economics College,2006(4). 